\title{
Morphology and Morphometry of Few Components of Limbic System of Brain of Surti Buffalo (Bubalus bubalis)
}

\author{
Alka Suman* and S.P. Pandya \\ Department of Veterinary Anatomy and Histology, College of Veterinary Science and A.H., \\ Anand Agriculture University, Anand, 388001, Gujarat, India \\ *Corresponding author
}

\section{A B S T R A C T}

The present study entitled "Morphology and Morphometry of few components of Limbic System of brain of Surti Buffalo (Bubalus bubalis)" was carried out at the Department of Veterinary Anatomy and Histology, College of Veterinary Science and A.H., Anand Agricultural University, Anand, Gujarat. For this study, 12 specimens of brain of buffaloes were used and few components of limbic system were recorded with the help of the scientific weighing balance, Vernier callipers, thread and scale. The limbic system is also called as an emotional brain. The few components of limbic system included the thalamus, fornix, hippocampus, caudate nucleus, septum pellucidum, amygdaloid body, and mammillary body. The thalamus was an oval shaped structure. The overall mean value of diameter of thalamus was $1.46 \pm 0.03 \mathrm{~cm}$. The fornix was bilateral structure of white fibers which consisted of body, two columns and two crura. The overall mean value of length of fornix was $8.03 \pm 0.1 \mathrm{~cm}$. The hippocampus was a curved elevation. The two hippocampi joined together by hippocampus commissure under the corpus callosum. The overall mean value of length and width of hippocampus was $7.77 \pm 0.09$ and $2.29 \pm 0.03 \mathrm{~cm}$ and width of hippocampal fimbriae at its widest region was $1.34 \pm 0.04 \mathrm{~cm}$. The caudate nucleus was one of the largest visible basal nuclei of brain. It was comma shaped nucleus of grey matter. The overall mean value of length and width of caudate nucleus was $5.7 \pm 0.09 \mathrm{~cm}$ and $2.31 \pm 0.03 \mathrm{~cm}$. The septum pellucidum was thin translucent membrane of two laminae which separates two lateral ventricles. The overall mean value of length and height of septum pellucidum was $3.6 \pm 0.12$ and $0.52 \pm 0.04 \mathrm{~cm}$. The cavum septum pellucidum was a small space between found two laminae of septum pellucidum. The amygdaloid body was oval shaped structure of grey matter. The overall mean value of diameter of amygdaloid body was $0.91 \pm 0.04 \mathrm{~cm}$. The mammillary body was a small round body of white matter. The overall mean value of diameter of mammillary body was $0.61 \pm 0.02 \mathrm{~cm}$.

\section{Introduction}

The Surti is a breed of water buffalo found in the Charottar tract of Gujarat between the
Mahi and Sabarmati rivers. The best animals of this breed are found in Anand, Kaira and Baroda districts of Gujarat (Banerjee, 2014). Limbic system is a collection of cortical and 
subcortical components of brain often referred as "visceral brain" because it has major visceral motor activity such as olfaction through piriform lobe, which leads to emotional behavior such as eating, rage(violent anger),sexual activity, fear, and drinking (LaBar and Cabeza 2006). The cortical structure are cingulate gyri, pyriform lobe and hippocampus. The sub cortical parts include thalamus hypothalamus and amygdaloid body (Konig et al., 2009). Amygdala is involved in the emotional response to smell while another limbic structure - the entorhinal cortex, is concerned with olfactory memories. The limbic structures are closely related to the olfactory cortex and have a role in the processing of olfactory sensation (Ganong, 2003).Present work aims to study the limbic system of brain of Surti buffalo because there is no significant data established on the morphology and morphometry of limbic system of brain of Surti buffalo.

\section{Materials and Methods}

The present study was carried out at the department of Veterinary Anatomy and Histology, College of Veterinary Science and Animal Husbandry, Anand Agricultural University, Anand, Gujarat. The materials required for the present study were collected from normal healthy adults Surti buffalo immediately after slaughter from the local slaughter house Anand as well as Municipal Corporation slaughter house Ahmedabad. The sample were preserved in 10 percent neutral buffered formalin at least for 24 hours. The measurements like length width, height, thickness and diameter of various structure of limbic system of brain were taken with the digital Vernier callipers, non- stretchable thread and scale. The means, standard errors and coefficients of variance were worked out (Snedcor and Cochran, 1994).

\section{Results and Discussion}

The components of limbic system included the thalamus, fornix, hippocampus, caudate nucleus, septum pellucidum, amygdaloid body, and mammillary body. These structures are shown in Figures and their biometry in Table 1.

\section{Thalamus}

The thalamus was an oval shaped structure of white matter located on dorsal surface of cerebral peduncles. There were two thalami, right and left, both were connected with fibers which was inter-thalamic adhesion. Both the thalami were surrounded by a smooth small circular groove which was third ventricle (Fig. 1).

Dipepan (1956) in African elephant, Trotter and Lumb (1962) in bovine, Getty (1975) in horse, Konig et al., (2009) Shrinivasan (2012) in bovine and Abedellah et al., (2015) in camel, mentioned that the thalamus was the largest part and the thalami were connected by the interthalamic adhesion, which was encircled by the third ventricle. The right and left thalmi are connected by a short, cylindrical group of fibers having a diameter of about a half inch. The connection is almost completely encircled by the third ventricle. The similar morphology of thalamus was found in Surti buffalo.

The overall mean value of diameter of thalamus was $1.46 \mathrm{~cm}$ with the range between 1.3 and $1.6 \mathrm{~cm}$.

\section{Fornix}

Fornix was bilateral structure of white fibers which consisted of body, two columns and two crura. The body was arched over the thalamus and third ventricle. the fornix presented two surfaces and two borders. The 
dorsal surface was smooth and convex and formed floor of lateral ventricle. The ventral surface was smooth and concave and placed above the thalamus. The medial border blended with laminae of septum pellucidum. The lateral border formed groove with the caudate nucleus and was present a choroid plexus. The fornix ended to the mammillary body of the ventral surface. The crura continued as fimbria along the margin of hippocampus (Fig. 2).

Trotter and Lumb (1962) in bovine, ICAR (1964) in ox, Getty, (1975) in horse, Shrinivasan, (2012) in ox, mentioned that fornix is a white body, consist of a body, two columns and two crura. The body overlies the anterior part of third ventricle. The columns are two rounded cords which diverge in front and bend ventrally and downward to enter mammillary body. The crura bends which diverge behind and are continued as the fimbria along the concave margin of hippocampus. Akers and Denbow, (2013) in domestic animals mentioned that fornix is a fiber tract running inferior to the corpus callosum and connecting the hippocampus with the hypothalamus where it ends in the mammillary bodies. It forms the roof of the third ventricle and the upper margin of the inerventricular foramen. The all above findings are similar to the findings in horse, ox and bovines of the fornix of the Surti buffalo.

The overall mean value of the length of the fornix was $8.03 \mathrm{~cm}$ with the range between 7 and $8.6 \mathrm{~cm}$.

\section{Hippocampus}

The hippocampus was a curved elevation which starts from the ventral aspect of piriform lobe and ends ventral to the splenium of the corpus callosum. The two hippocampi join together by hippocampus commissure under the corpus callosum. The fimbriae of the hippocampus were attached to the fornix (Fig.
$3 \mathrm{a}, \mathrm{b}$ and $\mathrm{c})$. These findings are similar to the ICAR (1964), Getty (1975) in horse, Cope (2010) in horse, Akers and Denbow (2013) in bovine, Kumaravel et al., (2014) in Indian buffalo. However, Getty (1975) in horse, Chen et al., (2009) in camel, Shrinivasan (2012) in ox reported that surface of the hippocampus was covered by a layer of white fibers, called alveus (Fig. 4) which was also observed in present study.

The overall mean value of the length of the hippocampus was $7.77 \mathrm{~cm}$ with the range between 7.1 and $8.2 \mathrm{~cm}$. The overall mean value of the width of hippocampus was 2.29 $\mathrm{cm}$ with the range between 2.1 to $2.45 \mathrm{~cm}$. Chen et al., (2009) reported that the whole length of hippocampus was about $6.0 \mathrm{~cm}$ in Bactrian camel, which was lesser than the present study.

The overall mean value of the width at the widest region of hippocampus fimbria was 1.34 with the range between 1.15 to $1.6 \mathrm{~cm}$. Zhu, (2002) in camel reported that the hippocampal fimbria was a smooth and flat white band attached to the concave surface of the hippocampus. The fimbria was small at the ventral end the size gradually increased when extending dorsally, the widest region of fimbria was about $1.2 \mathrm{~cm}$. the values are at par with the width of the fimbriae of the hippocampus of the Surti buffalo in present study.

\section{Caudate nucleus}

All the basal nuclei were located deep within the cerebral hemisphere in the telencephalon. The Caudate nucleus was one of the largest and visible basal nuclei of the brain. It was comma shaped nucleus of grey matter which was placed obliquely. The caudate nucleus present two parts head and tail: The head was on the anterolateral aspect while the tail was on the posterolateral aspect of the lateral ventricle (Fig. 4). It forms floor of the central 
body of lateral ventricle. The medial border of nucleus was placed near the thalamus, where it forms groove with the white matter of fornix in which the choroid plexus of lateral ventricle was placed (Fig. 5). The above findings were in accordance with ICAR (1964) in ox, Getty (1975) in horse, Zhaohui et al., (2011) in Bactrian camel, Srinivasan (2012) in ox. But according to Getty and Zhaohui et al., caudate nucleus was pear shaped in horse and camel.

The overall mean value of the length of the caudate nucleus from head to tail was $5.7 \mathrm{~cm}$ with the range between 5.35 and $5.9 \mathrm{~cm}$. The overall mean value of the width of caudate nucleus was $2.31 \mathrm{~cm}$ with the range between 2.15 to $2.45 \mathrm{~cm}$. Abedellaah et al., (2015) studied brain of one humped camel and reported that the caudate nucleus is a large grey mass of about $20 \mathrm{~mm}$ in length and 10 $\mathrm{mm}$ in width forming the floor of the lateral ventricle together with the more developed hippocampus. In present findings, the length and width of the caudate nucleus was $57 \mathrm{~mm}$ and $23 \mathrm{~mm}$ respectively which was more than the caudate nucleus of camel.

\begin{tabular}{|c|c|c|c|c|}
\hline SI. No. & Parameters & Range & Mean \pm SE & C.V \% \\
\hline \multirow[t]{2}{*}{1} & \multicolumn{4}{|l|}{ Fornix } \\
\hline & Length $(\mathrm{cm})$ & 7 to 8.6 & $8.03 \pm 0.13$ & 5.47 \\
\hline \multirow[t]{3}{*}{2} & \multicolumn{4}{|l|}{ Hippocampus } \\
\hline & Length $(\mathrm{cm})$ & 7.1 to 8.2 & $7.77 \pm 0.09$ & 4.12 \\
\hline & Width $(\mathrm{cm})$ & 2.1 to 2.45 & $2.29 \pm 0.032$ & 4.80 \\
\hline \multirow[t]{2}{*}{3} & \multicolumn{4}{|l|}{ Hippocampal Fimbrae } \\
\hline & Width $(\mathrm{cm})$ & 1.15 to1.6 & $1.34 \pm 0.04$ & 10.45 \\
\hline \multirow[t]{3}{*}{4} & \multicolumn{4}{|l|}{ Amygdaloid Body } \\
\hline & Length $(\mathrm{cm})$ & 0.75 to 1.31 & $0.98 \pm 0.04$ & 15.31 \\
\hline & Width $(\mathrm{cm})$ & 0.55 to 0.8 & $0.66 \pm 0.03$ & 13.64 \\
\hline \multirow[t]{2}{*}{5} & \multicolumn{4}{|l|}{ Thalamus } \\
\hline & Diameter (cm) & 1.3 to 1.6 & $1.46 \pm 0.03$ & 6.16 \\
\hline \multirow[t]{3}{*}{6} & \multicolumn{4}{|l|}{ Caudate Nucleus } \\
\hline & Length (cm) & 5.35 to 5.9 & $5.7 \pm 0.09$ & 5.09 \\
\hline & Width $(\mathrm{cm})$ & 2.15 to 2.45 & $2.31 \pm 0.03$ & 4.76 \\
\hline \multirow[t]{2}{*}{7} & \multicolumn{4}{|l|}{ Mammillary Body } \\
\hline & Diameter $(\mathrm{cm})$ & 0.5 to 0.75 & $0.61 \pm 0.02$ & 13.11 \\
\hline
\end{tabular}


Fig.1 Photograph showing thalamus: (T) Thalamus,(ITA) Inter-thalamic adhesion,(3V) Third Ventricle, (IVF) Interventricular Foramen, (AC) Anterior Commissure, (F) Fornix and (PG) Pineal Gland

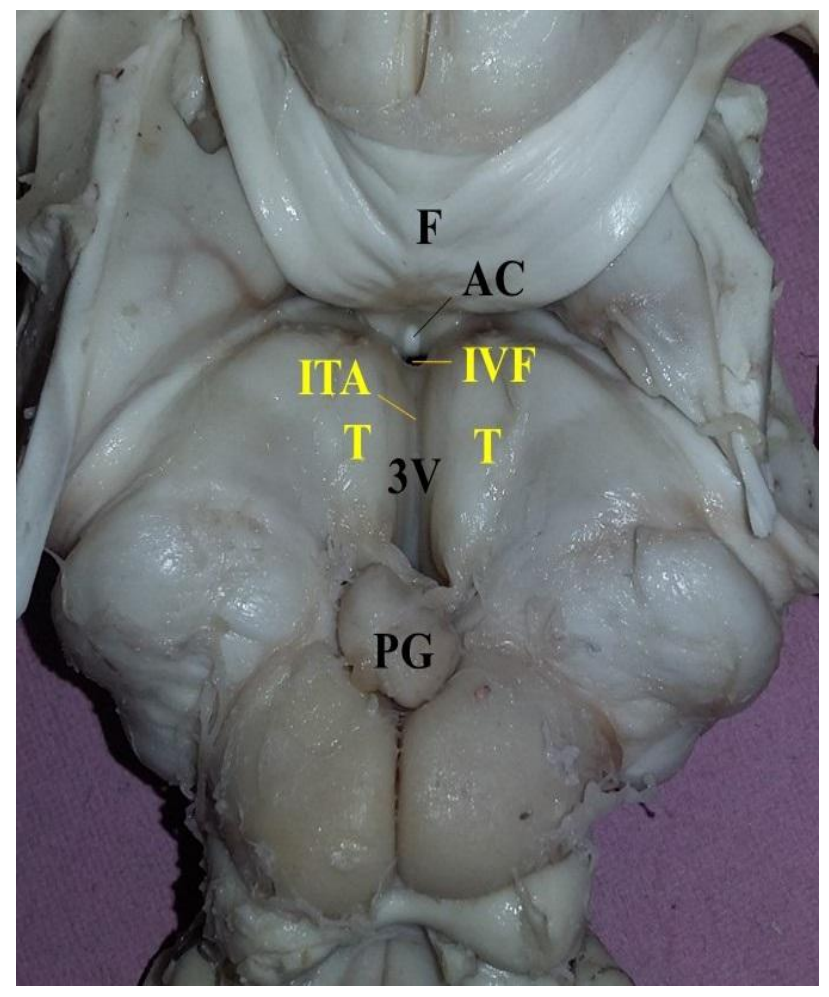

Fig.2 (a) Dorsal and (b) Ventral surface of fornix showing ( $\mathrm{Fcl}$ ) Column of fornix, $(\mathrm{Fb})$ Body of fornix, (Frr) Crura of fornix, (Fm) Fimbrae, $(\mathrm{H})$ Hippocampus and $(\mathrm{CN})$ Caudate Nucleus

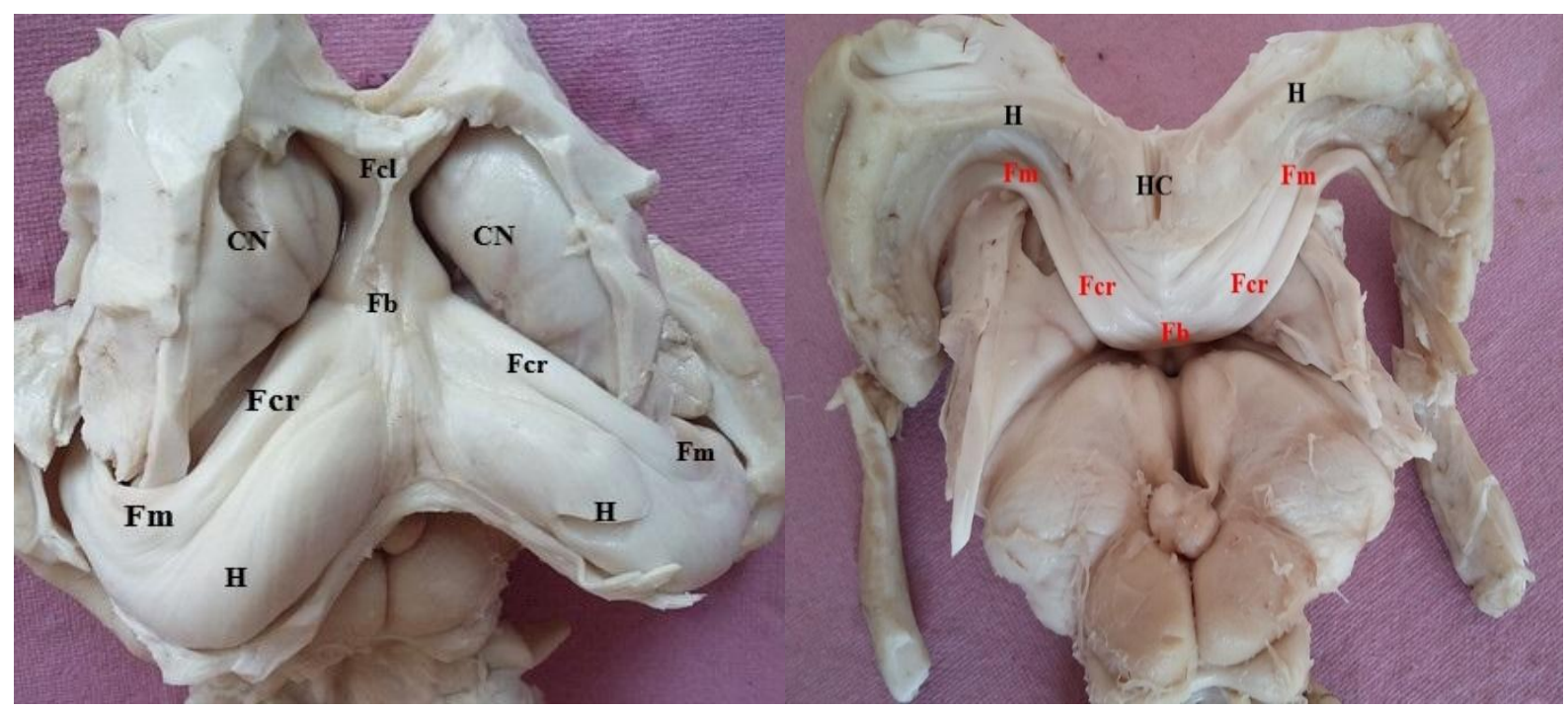


Fig.3 Photograph of Hippocampus (a) Position of hippocampus in brain showing:(CN) Caudate nucleus, (F) Fornix, (CP) Choroid plexus, (PG) Pineal gland (SC) Superior colliculi, and (IC)

Inferior colliculi. (b)\& (c)Dorsal and ventral surface of hippocampus showing:(HC) hippocampus commissure, (Fm) Fimbrae
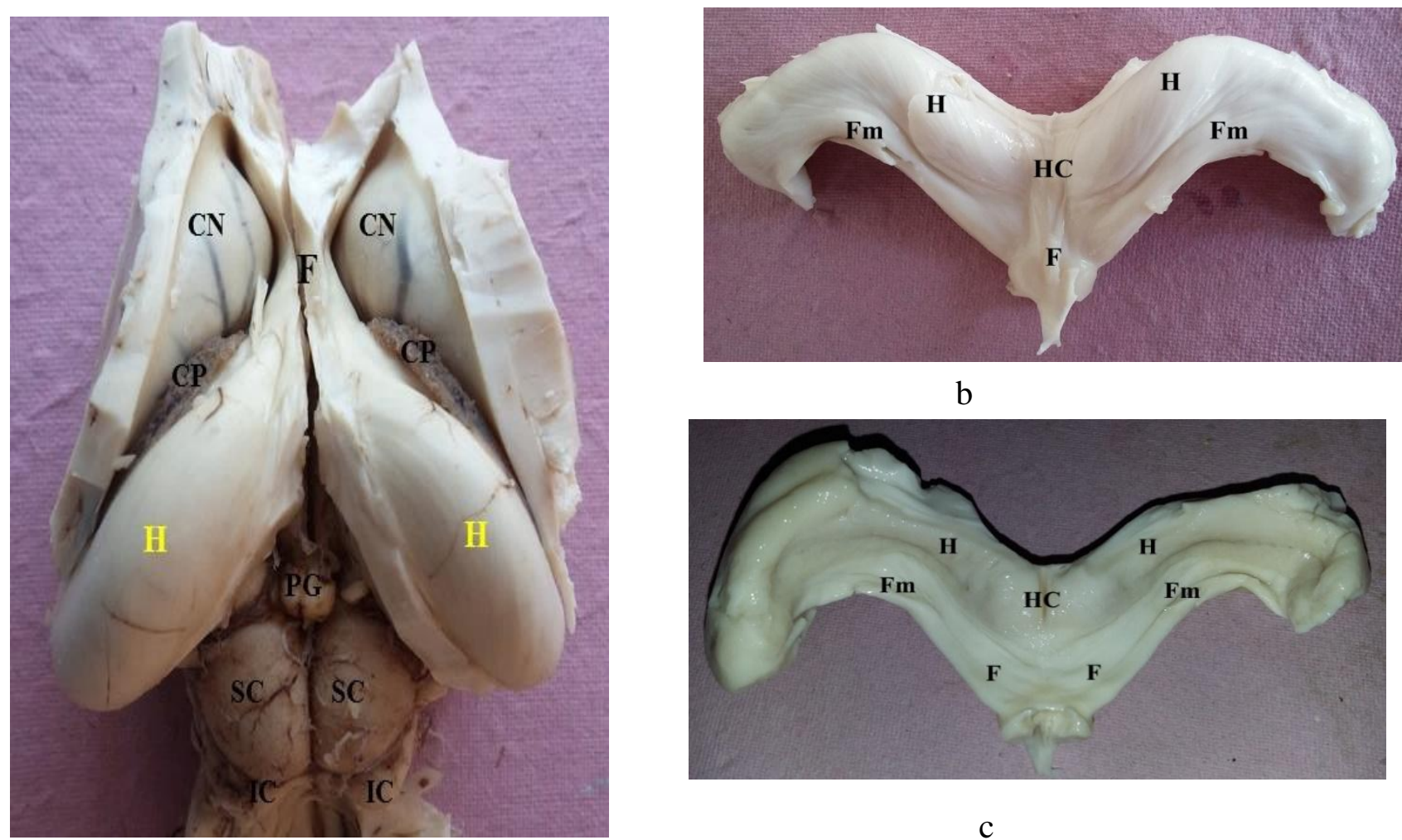

b

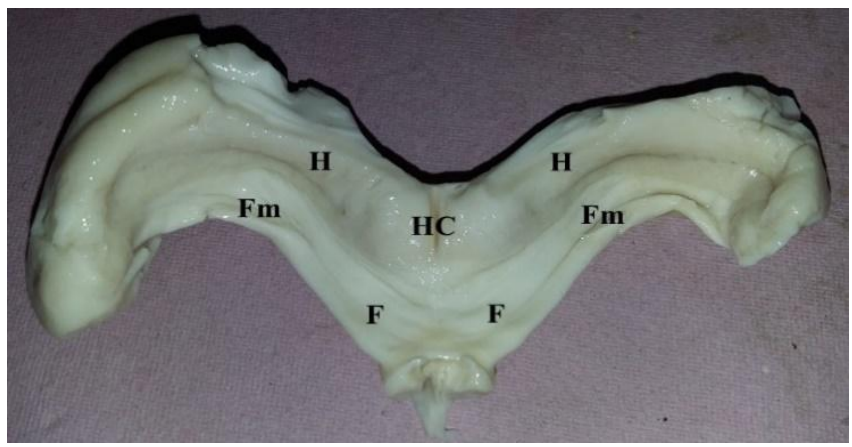

c

a

Fig.4 Structures of the Limbic system of the brain showing: (CN) Caudate Nucleus, (CNh) Caudate Nucleus head, (CNt) Caudate Nucleus tail,(H) Hippocamous, (AL) Alveus and (F) Fornix

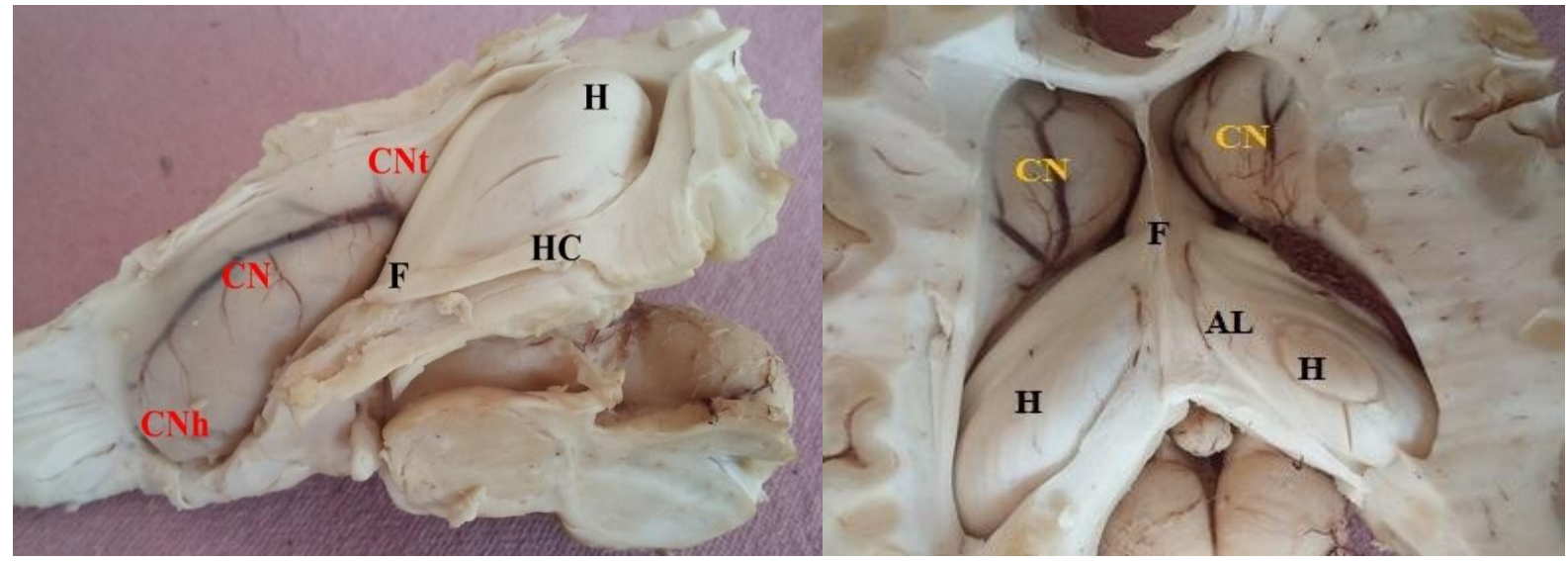


Fig.5 Photograph of (SP) Septum pellucidum, showing (CSP) Cavum septum pellucidum (LV) Lateral ventricle and (CP) Choroid plexus

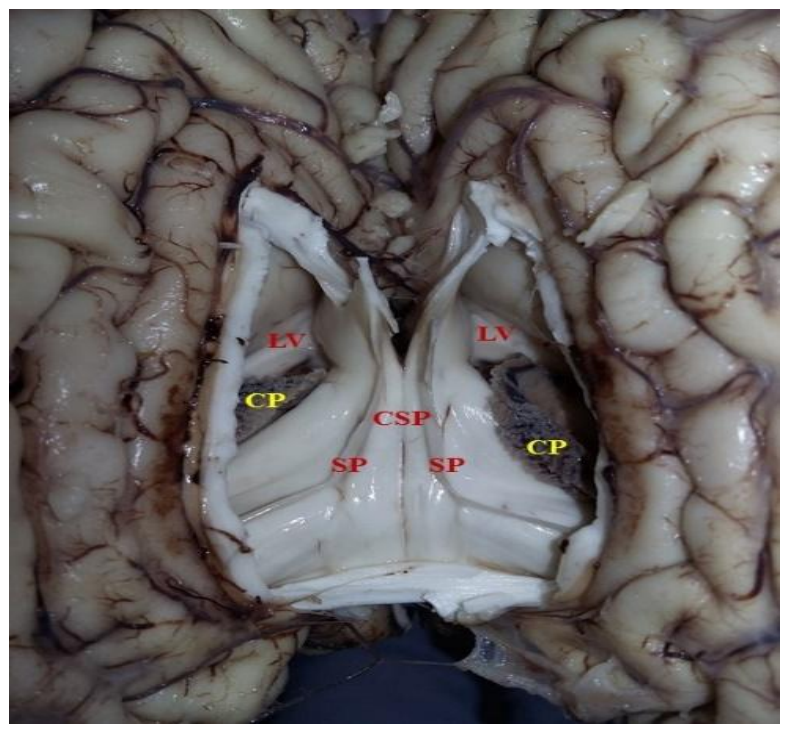

Fig.6 Photograph of (AB) Amygdala along with Fimbrae (Fm), Hippocampus (H)

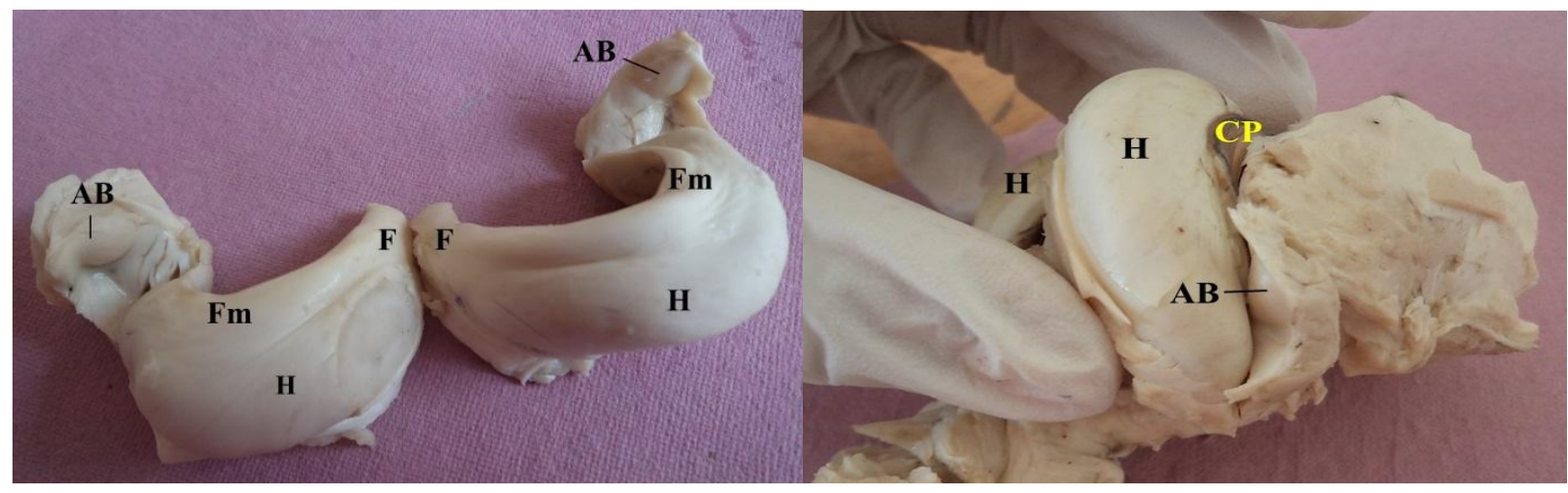

Fig.7 Photograph showing (MB) Mammillary Body, (3V) Third Ventricle, (CA) Cerebral Aqueduct, (T) Thalamus and (Tg) Tegmentum.

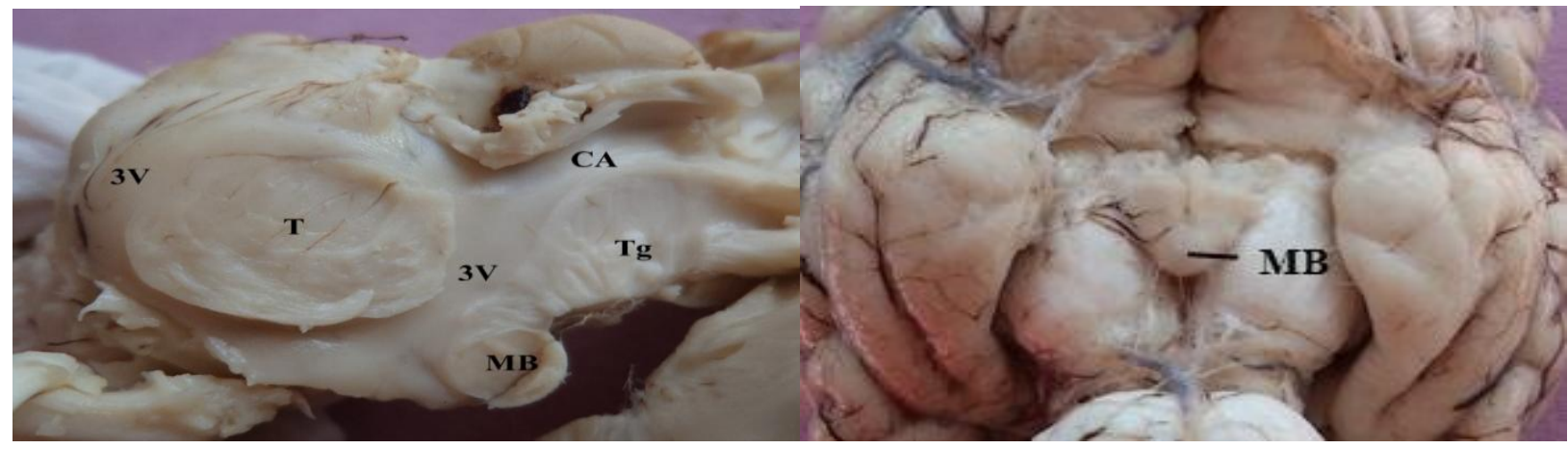




\section{Septum pellucidum}

Septum pellucidum was thin translucent membrane of two laminae which separates the two lateral ventricles. The dorsal surface of it attached with corpus callosum while ventral surface was attached with fornix. The septum starts from the cranial parts of the corpus callosum, the genu and it ends at caudal end of corpus callosum, the splenium. The cavum septum pellucidum is a closed triangular space between two laminae of the septum pellucidum (Fig. 5). It lacks cerebrospinal fluid and choroid plexuses.

The two leaves of septum pellucidum where apart from each other with little distance.Trotter and Lumb (1962) in bovine, ICAR (1964) in ox, Getty (1975) in horse Sarwar (1989) in human, Lucy et al., (2008) in goat and Shrinivasan (2012) in bovine, mentioned that the septum pellucidum is a median partition which separates the lateral ventricles and remains attached to the corpus callosum dorsally and fornix ventrally. These findings are parallel with the present findings. But all three above authors did not mention anything about cavum septum pellucidum. Sarwar (1989) in human reviewed that the cavum septum pellucidum is not a part of subarachnoid space nor is a part of ventricular system. The two leaves of septum pellucidum at least a $1 \mathrm{~mm}$ apart.

The overall mean value of the length and height of the septum pellucidum was 3.6 and 0.52 with the range between 3.0 to $4.3 \mathrm{~cm}$ and 0.3 to 0.65 $\mathrm{cm}$. Lignereux et al., (1987) measured the height of septum pellucidun from two different levels, at the interventicular foramen and above the hippocampus which was 2.5 to $9 \mathrm{~mm}$ and 0 to $5-6 \mathrm{~mm}$ in Friesian Cow. The values of length and width are higher in present study than the Friesian Cow.

\section{Amygdaloid body}

Amygdala was an oval shaped structure of the grey matter. It is located anterior of the hippocampus and close to the tail of the caudate nucleus (Fig. 6). Getty (1975) in horse, Dyce et al., (2009) in canines, Zhaohui et al., (2011) in Bacterian camel, Kumaravel et al., (2013) in Indian buffalo reported that the amygdala was oval to almond shaped grey mass and located near the tail of the caudate nucleus.

However, Sisson and Grossman in horses mentioned that the amygdala was located ventral to the posterior part of the lenticular nucleus in horses. The findings of the present study are in accordance with all above authors.

The overall mean value of the length of the amygdaloid body was $0.98 \pm 0.04 \mathrm{~cm}$ with the range between 0.75 to $1.31 \mathrm{~cm}$. The overall mean value of the width of amygdaloid body was $0.66 \pm 0.03 \mathrm{~cm}$ with the range between 0.55 to $0.8 \mathrm{~cm}$. Zhaohui et al., (2011) reported in camel that the diameter of amygdala was $1 \mathrm{~cm}$. the present values are lower than the Zhaohui et al.

\section{Mammillary Body}

The mammillary body was a small round body of white matter located on ventral surface of the anterior end of an interpeduncular fossa.

It is a single body in the external appearance. (Fig. 7). These findings were similar with the Sisson and Grossman (1950) in ruminats, ICAR (1964) in ox, Getty (1975) in horse.

The overall mean value of diameter of mammillary body was $0.61 \pm 0.02 \mathrm{~cm}$ with the range between 0.5 and $0.75 \mathrm{~cm}$.

\section{Acknowledgment}

We thank the authorities of Slaughterhouse, Ahmedabad Municipal Corporationfor brain specimen of adult Surti buffaloes provided, and Dean, College of Veterinary Science and AH, AAU, Anand, for all the facilities provided to carry out this study.

Conflict of Interest: All authors declare no conflict of interest. 


\section{References}

Abedellah, B.A., Awaad, A.S., Elhawari, S.F. and Sharshar, A.M. (2015). Normal brain of one-humped camel: a study with magnetic resonance and gross dissection anatomy! Indian Journal Veterinay Surgery,36 (1), 46-50.

Akers, R. M., and Denbow, D. M. (2013). Anatomy and Physiology of Domestic Animals. U.S.A Wiley Blackwell, pp. 241-264.

Banerjee, G.C. (2014). Buffalo. In: A Text Book of Animal Husbandry, ( $8^{\text {th }}$ ed., pp. 694-727). New Delhi, India: Oxford and IBH.

Chen, J., Bai, Z., Gao, Z. and Wang, J. (2009). Morphology of Rhinencephalon and Hippocampal formation of the Bactrian Camel (Camelus bactrianus) with their adaptive features! Vet Res Commun. 33, 25-32.

Cope, L.A. (2010). Dissection of the hippocampus proper and the associated structure in preserved horse brains! The Journal of Undergraduate Neuroscience Education,9(1), 43-46.

Diepen, R., Janssen, P., Engelhardt, F.R. and Spatz, H. (1956). Research on brain of African elephant (Loxodonta africana blum), Acta Neurol, Psychiatr Belg, 56, 759-787.

Dyce, K. M., Sack, W. and Wensing, C.J.G. (2009). Textbook pf Veterinary Anatomy. ( $3^{\text {rd }}$ ed.). Elsevier Inc, Noida.

Ganong WF(2003). Review of medical physiology: Smell and taste. (21st ed.). McGraw Hill Companies Inc; pp. 188-91.

Getty. R. (1975). Sisson and Grossman's: The Anatomy of the Domestic Animal. Volume 2. $\left(5^{\text {th }}\right.$ ed., pp. 1211). W.D. Saunders Company, Philadelphia.

ICAR, (1964). Neurology: Anatomy of the ox. Indian Council of Agriculture Research. New Delhi, India, pp. 624-645.
Konig, H.E., Liebich, H.G., and Cerveny, C. (2009). Veterinary Anatomy of Domestic mammals Text Book and Color Atlas, $\left(4^{\text {th }}\right.$ Ed., pp. 489-518). Germany.

Kumarvel, A., Geetha, R., Rajathi, S., Muthukrishnan, S., and Ramakrishnan V. (2014). Macroanatomy of hippocampus in buffaloes! Indian Journal Veterinary and Animal Science, 43 (5), 369-371.

LaBar K.S., and Cabeza R. (2006). Cognitive neuroscience of emotional memory. Nat Rev Neurosci, 7, 54-64.

Lignereux, Y., Fargeas, J., Marty, H., and Benard, P. (1987). Cerebral ventricles of the Friesian cow (Bos Taurus L.)!Anata anat, 128, 89-92.

Lucy, K.M., Harshan, K.R., Chungarth, J.J., and Ashok, N. (2008). Prenatal development of the ventricular system of brain in goats! Tamilnadu Journal of Veterinary and Animal Science,4 (1): 5-12.

Sarwar, M., (1989). The Septim pellucidum! American Journal of Neuroradiology, 10, 989-1005.

Sisson, S. and Grossman, J.D. (1950). Ruminant Nervous System. In The Anatomy of the Domestic Animals. W.B.Sounders, U.S.A, pp.788-813.

Snedecor, G.W. and Cochran, W.G. (1994). Statistical Methods. $14^{\text {th }}$ edn, The Iowa State Univ. Press, Ames, Iowa, USA.

Srinivasan, P. (2012). Veterinary Anatomy of $O x$. Bio Green Books, New Delhi, pp. 9-15.

Trotter, D. M. and Lumb, J. W. (1962). Bovine Anatomy. (2 $2^{\text {nd }}$ edn., pp. 203-220). Burgess Publishing Company.

Zhaohui, X., Qiusheng, S., Lei, Z., and Jianlin, W. (2011). Macroanatomy of basal nuclei in bacterian camel (Camelus bactrianus)! Journal of Camel Practice and Research,18(1), 141-144.

Zhu, C. G. (2002). Neuroanatomy. The hippocampal formation.( $1^{\text {st }}$ ed.).People's health press. pp. 7123-718.

\section{How to cite this article:}

Alka Suman and Pandya, S.P. 2018. Morphology and Morphometry of Few Components of Limbic System of Brain of Surti Buffalo (Bubalus bubalis). Int.J.Curr.Microbiol.App.Sci. 7(07): 622-630. doi: https://doi.org/10.20546/ijcmas.2018.707.075 